\title{
Effect of non-surgical periodontal therapy on the levels of C-reactive protein: a pilot study
}

\author{
Efeito da terapia periodontal não-cirúrgica nos níveis séricos \\ de proteína C-reativa: estudo piloto
}

\begin{abstract}
Purpose: C-reactive protein (CRP) is a marker of inflammation that is naturally present in the plasma at levels that may rise due to inflammatory processes, associated with a greater risk of cardiovascular events such as acute myocardial infarction. Periodontal disease is responsible for a host immune-inflammatory response, contributing towards clarifying its association with cardiovascular disease. The aim of this study was to investigate the effect of periodontal therapy on the levels of this inflammatory marker.

Methods: The sample consisted of 62 patients of both genders, between the ages of 30 to 60 years, who were referred to dental treatment at the Bahia Foundation for the Development of Sciences, and they were divided into two groups: with and without periodontitis. The clinical descriptors used were the bleeding index, gingival recession, probing depth and clinical attachment level. For CRP analysis, peripheral blood was collected from these individuals and sent to a single clinical analysis laboratory.

Results: The group with periodontitis was treated and the results showed that there was a statistically significant difference between the CRP levels before and after periodontal treatment $(P<0.05)$.

Conclusion: From the final findings, it may be concluded that non-surgical periodontal therapy showed a tendency to reduce the CRP serum levels.
\end{abstract}

Key words: Periodontal disease; C-reactive protein; cardiovascular disease

\section{Resumo}

Objetivo: Proteína C-Reativa (PCR) é um marcador de inflamação presente no plasma cujos níveis podem se elevar devido a um processo inflamatório, ocasionando um maior risco a eventos cardiovasculares, como o Infarto Agudo do Miocárdio. A doença periodontal promove uma resposta imuno-inflamatória do hospedeiro, contribuindo com níveis mais elevados de PCR, esclarecendo sua associação com a doença cardiovascular. Objetivou-se neste estudo verificar o efeito da terapia periodontal nos níveis desse marcador inflamatório.

Metodologia: A amostra constou de 62 pacientes, de ambos os sexos, com faixa etária entre 30 e 60 anos, encaminhados para tratamento odontológico na Fundação Bahiana para Desenvolvimento das Ciências, e distribuídos entre dois grupos: com e sem periodontite. Os descritores clínicos empregados consistiram de Índice de Sangramento, Recessão Gengival, Profundidade de Sondagem e Nível de Inserção Clínica. Para a análise da PCR foi coletado sangue periférico dos indivíduos e encaminhados a um mesmo laboratório de análises clínicas.

Resultados: $O$ grupo com periodontite foi tratado e os resultados mostraram que houve diferença estatisticamente significante entre os níveis de PCR antes e após o tratamento periodontal $(P<0,05)$.

Conclusão: De acordo com os achados finais, pode-se concluir que a terapia periodontal não cirúrgica apresentou uma tendência de redução dos níveis séricos da PCR.

Palavras-chave: Doença periodontal; proteína C-reativa; doença cardiovascular

\author{
Camila Oliveira Teixeira de Freitas ${ }^{a}$ \\ Isaac Suzart Gomes-Filho b \\ Roberta Catapano Naves a \\ Simone Seixas da Cruz ${ }^{\circ}$ \\ Carlos Antonio de Souza Teles Santos c \\ Mônica Dourado da Silva Barbosa a
}

a Bahia School of Medicine and Public Health, Salvador, BA, Brazil

bState University of Feira de Santana, Feira de Santana, BA, Brazil

CInstitute of Public Health, Federal University of Bahia, Salvador, BA, Brazil

\author{
Correspondence: \\ Camila Oliveira Teixeira de Freitas \\ Av. Getúlio Vargas, 379, Centro \\ Feira de Santana, BA - Brazil \\ 44025-010 \\ E-mail: camila.otf@gmail.com
}

Received: October 14, 2010

Accepted: November 29, 2010

Conflict of Interest Statement: The authors state that there are no financial and personal conflicts of interest that could have inappropriately influenced their work.

Copyright: (C) 2011 Freitas et al.; licensee EDIPUCRS. This is an Open Access article distributed under the terms of the Creative Commons AttributionNoncommercial-No Derivative Works 3.0 Unported License. 


\section{Introduction}

Periodontal disease is an inflammatory process with the presence of edema, redness and gingival bleeding, a clinical condition compatible with gingivitis that, as it progresses, causes the resorption of the alveolar bone tissue, destruction of the cementum and periodontal ligament, characterizing periodontitis. The progression of the disease occurs unpredictably, with site specific breakdown, and if left untreated, it may lead to the loss of teeth (1).

The degree of severity of this oral infection seems to be determined, in the first place, by the magnitude of the host inflammatory response (2), that is, by chemical mediators of the immunological system that act in the natural course of the periodontal disease. This is one of the basis that supports the hypothesis that persistent bacterial attacks, associated with irregular host inflammatory response, may have consequences beyond the periodontal tissues and may even influence the occurrence of some systemic diseases $(2,3)$.

Periodontitis is a chronic infection capable of inducing an inflammatory response that increases the level of proteins during the acute phase, such as C-reactive protein, and considering that these proteins are independent risk factors for cardiovascular diseases, this could explain the connection between periodontal disease and heart disease that is, periodontal diseases increase the risk of cardiovascular diseases. It must be emphasized that the CRP concentration between 1 and $3 \mathrm{mg} / \mathrm{L}$ is considered medium risk and more than $3 \mathrm{mg} / \mathrm{L}$ an increased risk of future cardiovascular events (4).

In view of the above-mentioned, the aim of this study was to establish non-surgical periodontal therapy in individuals with periodontitis and compare the CRP serum levels before and after treatment in an endeavor to verify whether treatment can interfere in the risk factor for cardiovascular disease.

\section{Methods}

\section{Selection of subjects for the sample}

The sample consisted of 62 subjects who were selected among those who attended the screening sector of the Dental Clinic of the Bahia Foundation for the Development of Sciences (FBDC), Cabula Campus, Salvador, BA, Brazil, from January to November 2007, between the ages of 30 and 60 years, who did not meet the exclusion criteria, and who agreed to participate in the study. The research protocol was approved by the Research Ethics Committee of FBDC, Salvador, BA, Brazil (protocol: 64/2006).

The exclusion criteria were as follows: less than 15 teeth in the mouth; a positive history of acute infections (colds, sinusitis, etc.) in the last two months; antibiotic or antimicrobial therapy in the last three months; use aspirins, anti-inflammatories or anticoagulants; be pregnant, a smoker or diabetic.

\section{Data Collection Procedures}

First, the participants answered a questionnaire during an interview containing the following items: identification, socio-demographic data, aspects related to general and oral health and life habits. Next a detailed clinical dental examination was carried out, including a complete periodontal examination on all participants at a dental office of the Dental School. All participants were examined by a single dentist, specialist in Periodontics, previously calibrated (Kappa $74.4 \%$ and $84.8 \%$ simple agreement). The selected individuals followed a research protocol depending on the diagnosis of periodontal disease.

The CRP serum levels were assessed by the hypersensitive immunonephelometric method, in the same clinical analysis laboratory, by the analysis of peripheral blood, obtained from the patient through venipuncture.

Periodontal treatment and maintenance was performed at the Dental Clinic of FBDC - Cabula Campus, by one graduate student.

\section{Periodontal exam}

All participants were submitted to a periodontal exam that occurred at time zero or at the time of periodontal diagnosis and repeated 45 days after periodontal treatment. In this exam the gingival index (GI) and plaque index (PI), probing depth, gingival recession and increase, and clinical attachment level for all teeth were measured. These measurements were taken at six different locations for each tooth (mesiobuccal, mid-buccal, distobuccal, mesiolingual, mid-lingual and distolingual) and recorded on a proper chart. All the measurements were performed with the aid of a Williams probe.

\section{Diagnosis of periodontal condition}

To diagnose the periodontal condition, the criterion adopted was the one used by López et al. (5), that considers that an individual has periodontitis if he/she presents at least 4 teeth with at least one site with probing depth of $\geq 4 \mathrm{~mm}$ and clinical attachment level of $\geq 3 \mathrm{~mm}$ in the same site.

Defining the groups

- Experimental Group: formed by individuals with a diagnosis of periodontitis and who were referred to periodontal treatment at the same Institution.

- Control Group: formed by individuals without a diagnosis of periodontitis and who were also referred to other dental treatments at the clinic of the Institution.

\section{Periodontal treatment}

The patients received guidance on oral hygiene and hygiene kits, followed by root scaling and planning of all teeth in a single session. The root scaling and planning procedures were performed manually with the aid of an ultrasound appliance. After the scaling session, the patients used a mouth wash containing $0.12 \%$ chlorhexidine for 1 minute. Each individual received a bottle containing $0.12 \%$ chlorhexidine solution for daily mouthwash to be used for 8 days, twice a day.

The individuals underwent periodontal maintenance therapy for 45 days, by means of fortnightly consultations, 
in which bacterial plaque control procedures were performed on the surfaces of the teeth and guidance on oral hygiene was given.

\section{Verification of CPR levels}

The samples for analysis of laboratory exams of CPR were taken at 3 times, through venipuncture, performed by the researcher. The first sample was collected during the initial exam (from both control and experimental group), the second and third samples were taken 8 days (6) and 45 days (7) after finishing the proposed periodontal therapy (but only from the experimental group). After collection, the blood was stored in a polystyrene box at room temperature, for a maximum of 2 hours, and then taken to the laboratory responsible for the analysis of the material. The definition of the CRP values was interpreted according to the following risk for cardiovascular diseases: high risk $(>3 \mathrm{mg} / \mathrm{L})$, medium risk (1 a $3 \mathrm{mg} / \mathrm{L})$ and low risk $(<1 \mathrm{mg} / \mathrm{L})(8)$.

\section{Other complementary exams}

Using the same sample of peripheral blood, collected to assess CPR, the levels of glucose, triglycerides, total cholesterol, HDL cholesterol, LDL cholesterol and complete leukogram were also verified, with the purpose of identifying patients with hyperlipidemia and infections during the experiment, which would be used to interpret the data.

\section{Data analysis procedures}

Initially, a bivariate analysis was conducted with the purpose of describing the socio-demographic characteristics of the control and experimental groups. Similarly, the clinical characteristics were described before and after periodontal treatment of the experimental group. For this purpose, the McNemar test and Fisher's Exact test were used to assess the categorical variables. The descriptive analysis of the clinical periodontal characteristics in control group as well as in the experimental group was also conducted before and after therapy. Afterwards, the differences in the reduction of CRP levels were verified (dependent variable), comparing the first measurement with the final one performed after periodontal treatment, using the paired Student's- $t$ test. To verify the effect of other considered co-variables (BMI, triglycerides, physical activity, HDL and BMI) in reducing C-reactive protein, the multivariate analysis with a linear regression model (ANCOVA) was used. Finally, the C-reactive protein measurements, before and after periodontal therapy, were compared with the experimental group and control group, using the Tukey multiple comparison test. The level of statistical significance adopted was 5\%. The SPSS version 10.0 and Stata version 7.0 statistical packages were used.

Since a sample calculation was not performed, the power calculation/sample size with regard to the case group was then obtained by using PS Power and Sample Size Calculation. Therefore, a power of $30 \%$ was found for the case group based on the sample size $(n=31)$ assessed. For this purpose, a level of significance of $5 \%$ was assumed, with a minimum significant difference of 0.74 and standard deviation of 2.7 obtained from the analysis of the sample itself.

\section{Results}

Sixty-two individuals were selected, 21 men and 41 women, who fitted into two groups according to their periodontal condition and in accordance with the following criteria adopted: experimental group (treated for periodontitis) and control group (without periodontitis), both groups with 31 individuals each.

Table 1 shows some characteristics of the population studied. In general, the individuals from the experimental group did not show statistically significant differences in comparison with the control group for most of the covariables, except for the educational level $(P=0.05)$, marital status $(P=0.04)$ and hypertension $(P<0.001)$. General mean age of the individuals was 39.8 years with mean age equal to 40 and 37 years for the experimental and control groups, respectively.

Table 1. General characteristics of the experimental group (treated for periodontitis) and control group (without periodontitis) $(n=62)$.

\begin{tabular}{|c|c|c|c|}
\hline \multirow[t]{2}{*}{ Characteristics } & $\begin{array}{l}\text { Control } \\
\text { Group }\end{array}$ & $\begin{array}{c}\text { Experimental } \\
\text { Group }\end{array}$ & \multirow[t]{2}{*}{$P$} \\
\hline & n (\%) & n (\%) & \\
\hline \multicolumn{4}{|l|}{ Age (years) } \\
\hline$<40$ & $20(64.5)$ & $17(54.8)$ & \multirow[t]{4}{*}{0.60} \\
\hline$\geq 40$ & $11(35.5)$ & $14(45.2)$ & \\
\hline Mean & 39.1 & 40.5 & \\
\hline Median & 37 & 40 & \\
\hline Interval & $29-60$ & $30-56$ & 0.51 \\
\hline \multicolumn{4}{|l|}{ Sex } \\
\hline Women & $20(64.5)$ & $21(67.7)$ & \multirow[t]{2}{*}{0.79} \\
\hline Men & $11(35.5)$ & $10(32.3)$ & \\
\hline \multicolumn{4}{|l|}{ Educational Level } \\
\hline High school/Graduate & $26(83.9)$ & $19(61.3)$ & \multirow[t]{2}{*}{0.05} \\
\hline Elementary & $5(16.1)$ & $12(38.7)$ & \\
\hline \multicolumn{4}{|l|}{ Marital Status } \\
\hline Married & $11(35.5)$ & $4(12.9)$ & \multirow[t]{2}{*}{0.04} \\
\hline Single/Divorced/Widow & $20(64.5)$ & $27(87.1)$ & \\
\hline \multicolumn{4}{|l|}{ Per capita income* } \\
\hline$<1$ minimum salary & $13(41.9)$ & $13(41.9)$ & \multirow[t]{2}{*}{1.00} \\
\hline$\geq 1$ minimum salary & $18(58.1)$ & $18(58.1)$ & \\
\hline \multicolumn{4}{|l|}{ Physical activity } \\
\hline Yes & $6(19.4)$ & $9(29.0)$ & \multirow{2}{*}{0.37} \\
\hline No & $25(80.6)$ & $22(71.0)$ & \\
\hline \multicolumn{4}{|l|}{ Hypertension } \\
\hline Yes & $30(96.8)$ & $14(45.2)$ & \multirow[t]{2}{*}{$<0.01$} \\
\hline No & $1(3.2)$ & $17(54.8)$ & \\
\hline \multicolumn{4}{|l|}{ Visit to the dentist } \\
\hline None & $4(12.9)$ & $3(9.7)$ & \multirow{2}{*}{0.69} \\
\hline Once or + & $27(87.1)$ & $28(90.3)$ & \\
\hline \multicolumn{4}{|l|}{ BMI } \\
\hline$<29.9$ & $27(87.1)$ & $26(83.9)$ & \multirow{2}{*}{0.72} \\
\hline$\geq 29.9$ & 4 (12.9) & $5(16.1)$ & \\
\hline
\end{tabular}

\footnotetext{
* Value of the minimum salary $\mathrm{R} \$ 380,00$ on the day of the data collection.
} 
In Table 2, an improvement in the periodontal condition of the individuals after treatment may be observed, recorded by the reduction in the gingival index to almost one third of the presence of bleeding being closer to the values observed in the control group.

Table 2. Distribution (\%) of the clinical periodontal conditions in the experimental group (treated for periodontitis), the initial exam and 45 days after treatment, and control group (without periodontitis) $(n=62)$.

\begin{tabular}{lccc}
\hline & \multicolumn{2}{c}{ Experimental } & Control \\
\cline { 2 - 4 } & $\begin{array}{c}\text { Initial exam } \\
(\%)\end{array}$ & $\begin{array}{c}45 \text { days after } \\
\text { treatment }(\%)\end{array}$ & $(\%)$ \\
\hline $\begin{array}{l}\text { Absence of periodontitis } \\
\text { (Probing Depth } \leq 4 \mathrm{~mm}+\text { Clinical attachment }\end{array}$ & 0.0 & 70.0 & 100.0 \\
level $\leq 3 \mathrm{~mm}$, in less than 4 teeth) & & & \\
Gingival Index & 0.6 & 0.2 & 0.2 \\
\hline
\end{tabular}

Fig. 1. Mean values and standard deviation of CRP in the experimental groups at different times of collection (CRP 1 - initial exam; CRP 2 - after 8 days; CRP 3 - 45 days after periodontal treatment) and control (without periodontitis). Values of $P \geq 0.05$ among the groups.

Figure 1 shows the mean values and standard deviation of CRP at different times of collection in the experimental group (initial exam $=2.93 \pm 3.02 \mathrm{mg} / \mathrm{dL}$; 8 days after treatment $=4.26 \pm 7.48 \mathrm{mg} / \mathrm{dL}$ and 45 days after treatment $=2.23 \pm 2.51 \mathrm{mg} / \mathrm{dL}$ ); and in the control group $(2.30 \pm 2.77 \mathrm{mg} / \mathrm{dL})$. An increase in the CRP values was observed after 8 days of treatment and a reduction in the values after 45 days. However, the values obtained at the initial exam in comparison with those after 8 and 45 days of periodontal therapy was not statistically significant, at a level of significance of $\alpha=5 \%$ (CRP $1 \times$ CRP 2: $p=0.08$; CRP $2 \times$ CRP 3: $P=0.08)$, as well as when the comparison was made between the values obtained at the initial exams and final exams (45 days), (CRP $1 \times$ CRP 3: $P=0.07)$. It was also observed that after periodontal treatment, the CRP values of the experimental group were similar to the ones found in the control group $(P=0.08)$.

\section{Discussion}

According to the main finding of this study, a reduction in the CRP serum levels after 45 days of periodontal treatment may be observed, although there was no statistical significance $(P=0.07)$. Yamazaky et al. (9) found a tendency toward a decrease in CRP level 3 months after periodontal treatment $(P=0.09)$.

It is important to emphasize that the treatment protocol used by Yamazaky et al. (9) included, in addition to the conventional therapy, periodontal surgery and the use of antibiotics when indicated, as in most studies found in the literature, and few studies used only the periodontal treatment protocol and conventional therapy without using antibiotics and periodontal surgery (10-12).

Since the level of significance found in this study was close to $5 \%$, it is worth mentioning some limitations 
of the present study. First, the small size of the sample investigated must be pointed out, which was confirmed by the power calculation (30\%). The difficulty in selecting individuals due to the rigid inclusion criteria, which led to a small convenience sample, may have significantly contributed to the results presented. Furthermore, although the sample size was not ideal, this fact did not prevent us from perceiving the influence of periodontal infection at a systemic level, shown by the reduction in the CRP serum levels after 45 days of periodontal therapy.

Moreover, the CRP serum levels increased after 8 days of treatment in comparison with the initial exam. This increase can be attributed to the type of treatment used, complete mouth scaling in a single session is a procedure that causes a typical acute phase response in a manner that the levels of markers increase by up to 10 times after the first day, present a tendency to return to normal values from the $3^{\text {rd }}$ to $7^{\text {th }}$ day, but only reach the initial values after the $1^{\text {st }}$ month (4). With regard to the CRP results achieved after periodontal treatment, they could be improved, since the type of periodontal treatment used was the non-surgical one in a single session, knowing that periodontitis, after reassessment, may need complementary non-surgical or surgical treatment at the sites in which the progression of periodontal disease was more severe and the therapy used may not have been sufficient to restore the periodontal tissues back to the condition of normality (13). In the studies investigated, only one study used surgical procedures as a form of treatment (9) and several used local or systemic antibiotics parallel to therapy (7,13-15).

On the other hand, due to the methodological limitations, care was taken to assure greater reliability of the findings. To select the individuals with a diagnosis of periodontitis, a stricter criterion was chosen in order to be able to define the sick individual from the non-sick one associated with different clinical periodontal descriptors: probing depth and clinical attachment level, minimizing the false positives. According to Gomes-Filho et al. (16), these diagnostic criteria show good specificity and sensitivity to diagnose periodontitis. However, it is emphasized that the criteria used present a dichotomous classification, not being able to assess the level of severity of the periodontal disease $(5,16)$, which would be important in this topic since the higher the severity of periodontitis the higher the CRP serum level $(17,18)$. This became unfeasible due to the small number of individuals involved in the research.

In this connection, the inclusion of the control group in this study was imperative. The results of the periodontal therapy were compared within the experimental group before and after applying treatment. This comparison group allows some important assumptions, in view of recognizing different levels of severity that the periodontal disease presents and consequently, the difficulty in establishing dichotomous clinical diagnostic criteria. Although the comparison between the experimental and control groups did not show significant differences before and after therapy, it may be speculated that there may have been a large number of individuals with borderline clinical diagnosis in the control group or the degree of severity in the experimental group (most with moderate severity) was not sufficient to verify the higher levels of CRP. In addition, with regard to the therapy in a single session, it may have not been sufficient to reduce all the clinical levels to the limits of normality. This finding, when compared with the control group, confirms the possibility of a larger number of individuals with a borderline clinical diagnosis in the referred group.

Another care adopted in the present study was the high sensitivity of the nephelometry technique used to assess CRP, being capable of detecting variations of even $0.2 \mathrm{mg} / \mathrm{L}$. In other studies on the subject, different techniques for assessing the levels of CRP were used, namely: nephelometry $(9,10)$, Elisa test $(7)$, immunoturbidimetric test $(11,12,15,19)$, unspecified high-sensitivity test from a commercial laboratory (14), a high sensitivity commercial kit for measuring CRP in humans (20).

C-reactive protein has shown to play a role in the pathogenesis of atherosclerosis and recent evidence linking periodontal disease with a high risk of atherosclerotic plaque formation is the main cause of all cardiovascular diseases. The reduction in the CRP serum levels obtained in this study included individuals in a risk classification for developing cardiovascular disease, taking them from the high risk group ( $\mathrm{CRP} \geq 3$ ) to medium risk group (CRP between 1 and 3 ), showing a statistical significance of these findings and in agreement with other studies available in the literature $(7,10,14,15,20)$.

Other factors that might be associated with the variation of CRP, such as BMI, age, hypertension, triglycerides and HDL were tested in a linear regression model in which the dependent variable was the final CRP value. It was observed that the initial CRP, age and HDL have an influence on the result of final mean value of CRP, justifying the application of modeling, although few studies have done this kind of adjustment (18,21-23).

Within the perspective on the issue, a recent systematic review (24) recommends caution for there are still no conclusive studies on a large scale investigating the effect of periodontal therapy on this acute phase protein. The authors also argue that CRP is a nonspecific inflammatory marker, sensitive to classic confounding factors to the study of periodontal disease and cardiovascular diseases, such as BMI, smoking, dyslipidemia, hypertension, requiring that these variables be adjusted at the time of analysis.

\section{Conclusions}

According to the methodology used and the limitations of this study, it was possible to conclude that non-surgical periodontal therapy showed a tendency toward a decrease in the CRP serum levels, although not being statistically significant. Therefore, complementary and well designed studies with an adequate sample size must be conducted to establish the real relationship between periodontal therapy and the CRP serum levels. 
1. Lindhe J. Tratado de Periodontia Clínica e Implantologia Oral. Rio de Janeiro: Guanabara Koogan; 2010.

2. Offenbacher S, Madianos PN, Champagne CM, Southerland J H, Paquette DW, Williams $\mathrm{RC}$ et al. Periodontitis-atherosclerosis syndrome: An expanded model of pathogenesis. Periodontal Res 1999,34:346-52.

3. Davenport ES, Williams CE, Sterne JAC. The east London study of maternal chronic periodontal disease and preterm low birth weight infants: study design and prevalence data. Ann Periodontol 1998;3:213-21.

4. D' Aiuto F, Ready D. Tonetti MS. Periodontal disease and C-reactive protein-associated cardiovascular risk. J Periodontal Res 2004;39:236-41.

5. López N J, Smith P C, Gutierrez J. Periodontal therapy may reduce the risk of preterm low birth weight in women with periodontal disease: a randomized controlled trial. J Periodonto 2002;73:911-24.

6. Pepys MB, Hirschfield GM. C-reactive protein: a critical update. J Clin Invest 2003; $111: 1805-12$

7. Mattila K, Vesanen $M$, Valtonen $V$, Nieminem $M$, Palosuo $T$, Rasi $V$ et al. Effect of treating periodontitis on C-reactive protein levels: a pilot study. BMC Infec Dis 2002;2:14712334

8. Pearson TA, Mensah GA, Alexander RW, Anderson JL, Cannon RO 3rd, Criqui M et al. Markers of inflammation and cardiovascular disease: application to clinical and public health practice: A statement for healthcare professionals from the Centers for Disease Control and Prevention and the American Heart Association. Circulation 2003;107: 499-511.

9. Yamazaki K, Honda T, Oda T, Ueki-Maruyama K, Nakajima T, Yoshie H et al. Effect of periodontal treatment on the $\mathrm{C}$-reactive protein and proinflammatory cytokine levels in Japanese periodontitis patients. J Periodontal Res 2005;40:53-8.

10. Ide M, Jagdev D, Coward PY, Crook M, Barclay GR, Wilson RF. The short-term effects of treatment of chronic periodontitis on circulating levels of endotoxin, $\mathrm{C}$-reactive protein tumor necrosis factor-alpha, and interleukin-6. J Periodontol 2004;75:420-8.

1 1. D'Aiuto F, Parkar M, Andreou G, Brett PM, Ready D, Tonetti S. Periodontitis and atherogenesis: Causal association or simple coincidence? J Clin Periodontol 2004;31:402-11.

12. D' Aiuto F, Nibali L, Mohamd-Ali V, Vallance P, Tonetti MS. Periodontal therapy: A novel non-drug-induced experimental model to study human inflammation. J Periodontal Res 2004;39:294-9.

13. Tonetti MS, D'Aiuto F, Nibali L, Donald A, Storry C, Parkar M et al. Treatment of periodontitis and endothelial function. N Engl J Med 2007;356:911-20.

14. Iwamoto Y, Nishimura F, Soga Y, Takeuchi K, Kurihara M, Takashiba S et al. Antimicrobial periodontal treatment decreases serum $\mathrm{C}$-reactive protein, tumor necrosis factoralpha, but not adiponectin levels in patients with chronic periodontitis. J Periodontol 2003;74:1231-6.

15. D' Aiuto F, Parkar M, Nibali L, Suvan J, Lessem J, Tonetti MS. Periodontal infections cause changes in traditional and novel cardiovascular risk factors: Results from a randomize controlled clinical trial. Am Heart J 2006;151:977-84.

16. Gomes Filho IS, Macedo TCN, Cruz SS, Soledade KR, Trindade SC, Sarmento VA. Comparação de critérios que determinam o diagnóstico clínico da doença periodontal. Rev Odonto Cienc 2006;21:77-81.

17. Fredriksson, Ml; Figueredo CMS, Gustafsson A, Bergström KG, Asman BE. Effect of periodontitis and smoking on blood leukocytes and acute-phase proteins. J Periodontol 1999; 70:1355-60

18. Noack B, Genco RJ, Trevisan M, Grossi S, Zambon JJ, Nardin ED. Periodontal infections contribute to elevated systemic c-reative protein level. J Periodontol 2001;72:1221-7.

19. D'Aiuto F, Nibali L, Parkar M, Suvan J, Tonetti MS. Short-term effects of intensive periodontal therapy on serum inflammatory markers and cholesterol. J Dent Res 2005;84:269-73.

20. Montebugnoli L, Sernidio D, Miaton RA, Prati C, Tricoci P, Melloni C et al. Periodontal health improves systemic inflammatory and haemostatic status in subjects with coronary heart disease. J Clin Periodontol 2005;32:188-92.

21. Loss BG, Craandijk J, Hoeck FJ, Wertheim-van Dillem PM, van der Velden U. Elevation of systemic markers related to cardiovascular diseases in he peripheral blood of periodontitis patients. J Periodontol 2000;71:1528-34.

22. Joshipura KJ, Wand HC, Merchant AT, Rimm EB. Periodontal disease and biomarkers related to cardiovascular disease. J Dent Res 2004;83:151-5.

23. Craig RG, Yip JK, So MK, Boylan RJ, Socransky SS, Haffajee AD. Relationship of destructive periodontal disease to the acute-phase response. J Periodontol 2003;74:1007-16.

24. Paraskevas S, Huizinga JD, Loos BG. A systematic review and meta-analyses on C-reactive protein in relation to periodontitis. J Clin Periodontol 2008;35:277-90. 